Article

\title{
Accelerated Degradation Behavior and Cytocompatibility of Pure Iron Treated with
} Sandblasting

Juncen Zhou ${ }^{\dagger}$, YuyunYang ${ }^{\S, \dagger}$, Micael Alonso Frank ${ }^{\dagger, \S}$, Rainer Detsch ${ }^{\S}$, Aldo R. Boccaccini ${ }^{\S}$, and SannakaisaVirtanen ${ }^{\dagger}$ ** $^{*}$

$\dagger$ Institute for Surface Science and Corrosion, Department of Materials Science and Engineering, University of Erlangen-Nuremberg, Germany

$\S$ Institute of Biomaterials, Department of Materials Science and Engineering, University of Erlangen-Nuremberg, Germany

Corresponding Author *E-mail: virtanen@ww.uni-erlangen.de

\begin{abstract}
Fe-base materials are of interest to be used in biodegradable implants. However, their corrosion rate in the biological environment may be too slow for the targeted applications. In this work, sandblasting is applied as a successful surface treatment for increasing the degradation rate of pure iron in simulated body fluid. Two sandblasting surfaces with different roughness present various surface morphologies but similar degradation products. Electrochemistry tests revealed that sandblasted samples have a higher corrosion rate as compared to bare iron, and even more noteworthy, the degradation rate of sandblasted samples remains significantly higher during long-term immersion tests. Based on our experimental results, the most plausible reasons behind the fast degradation rate are the special properties of sandblasted surfaces including the change of surface composition (for the early stage), high roughness (occluded surface sites), and high density of dislocations.

Furthermore, the cytocompatibility was studied on sandblasting surfaces using human
\end{abstract}


osteoblast-like cells (MG-63) by indirect and direct contact methods. Results revealed that sandblasting treatment brings no adverse effect to the growth of MG-63 cells. This work demonstrates the significant potential of sandblasting for controlling the degradation behavior of iron-based materials for biomedical applications.

Keywords: Pure iron; Implant; Sandblasting; Degradation behavior; Cytocompatibility.

\section{Introduction}

Biodegradable metallic materials have drawn significant attention because their biodegradation can avoid the second surgery which is applied to remove temporary implants that are only required to remain in the body for the time of healing. Due to their excellent biocompatibility and mechanical properties, iron-based and magnesium-based materials are two promising metals to be adopted as biodegradable implants. ${ }^{1-4}$ Biodegradation behavior is a critical factor for the clinical performance of implants. For the application of magnesium and its alloys, the current major hindrance is their high degradation rate. This could cause an early mechanical failure and excess hydrogen evolution. ${ }^{5,6}$ Thererefore, a significant amount of research has been carried out on approaches to suppress the degradation rate of Mg-based materials (see, for example ${ }^{7,8}$ ).

On the contrary, a major disadvantage for iron-based materials is their relatively slow degradation rate. After implantation into the human body, materials should completely degrade during the time required for healing, to minimize possible negative long-term effects of the foreign body. For instance, for cardiovascular stents, the appropriate degradation period is approximately12-24 months. ${ }^{9}$ Several published works have focused on possible approaches to increase the degradation rate of iron-based materials. In general, strategies to accelerate the degradation rate of iron mostly focus on two aspects, alloying design and surface treatments. Hermawan et al. ${ }^{10,11}$ developed a Fe-Mn alloy containing 35 wt.\% Mn and 
Schinhammer et al. ${ }^{2,12}$ studied Fe-10Mn-1Pd (in wt.\%) alloy and Fe-Mn-C-Pd alloys. These alloys possess faster degradation rates compared to pure iron. Liu et al. ${ }^{13}$ discussed the effect of several alloying elements (Mn, Co, Al, W, Sn, B, C and S) on the degradation of pure iron. Moreover, Obayi et al. ${ }^{14}$ studied the degradation behavior of cross-rolled samples.

Only few investigations focusing on surface treatments of pure iron can be found in the literature. Cheng et al. ${ }^{15}$ used micro-patterned Au disc arrays to accelerate degradation of pure iron, based on galvanic corrosion caused by the Au array. Zhu et al. ${ }^{16}$ prepared $\mathrm{Fe}-\mathrm{O}$ thin films on pure iron by plasma immersion ion implantation and deposition to improve the biocompatibility, but in this case the corrosion resistance was improved.

It is well-known that surface roughness, which could affect both degradation behavior and biocompatibility, is a critical property for biomaterials. ${ }^{17-19}$ There are several ways to achieve rough surfaces, such as etching, grinding, and sandblasting. Frank et al. ${ }^{20}$ created a superhydrophobic surface on stainless steel by a sandblasting process combined with chemical modification. In their work, SiC particles with three different diameters were used for blasting to create surfaces with different roughness. Sandblasting is a facile and low-cost method, which can transform a flat surface into one with certain roughness. The influence of sandblasting treatment on in vitro corrosion resistance of titanium has been studied before. ${ }^{18}$ Gradients fabricated using sandblasting were used to investigate the response of cells to roughness. ${ }^{21}$ Moreover, sandblasting treatment was adopted to enhance in vitro biocompatibility of a NiTi alloy. ${ }^{22}$

The surface morphology of sandblasted samples could have a significant effect on corrosion and degradation behavior. In addition, the high dislocation density caused by sandblasting could also influence surface properties of materials. ${ }^{14,23}$ The surface morphology is generally considered to be related to the cytocompatibility of implants. The surface 
roughness can influence cell adhesion and cell proliferation; ${ }^{24}$ therefore it is crucial to evaluate the cytocompatibility of sandblasted samples.

In our study, we investigated the influence of sandblasting of pure iron surfaces on the corrosion behavior in simulated body environment. To the best of our knowledge, this is the first time that sandblasting is applied on pure iron from a biodegradable materials point of view. The present work focuses on the degradation behavior and biocompatibility of pure iron treated with sandblasting.

\section{Materials and methods}

\subsection{Materials}

Pure iron foil (purity $99.5 \%$, thickness $0.125 \mathrm{~mm}$ ) was purchased from Advent Research Materials Ltd. Iron foils were cut into $1.8 \times 1.8 \mathrm{~cm}$ pieces, subsequently cleaned by acetone, ethanol, and dried in nitrogen.

\subsection{Sandblasting process}

Iron samples were initially ground until 2000 grade with SiC papers. Afterwards they were sandblasted with a Cemat NT4 sandblasting device. Two particle sizes, F80 and F320, were used and their mass distribution is shown in Tables 1 and 2, and iron foils treated by these two particles were named as F80 sample and F320 sample, respectively. The sand was blasted perpendicular to the sample at a distance of $10 \mathrm{~cm}$ with a speed of $0.5 \mathrm{~cm} \mathrm{~s}^{-1}$. Afterwards samples were rinsed and sonicated for 10 minutes using ethanol, and finally dried in nitrogen. The surface roughness of the bare iron, F320 and F80 samples was measured by means of a laser profilometer (UBM, ISC-2).

\section{Table 1}


SiC grain mass distribution for particles F80 according FEPA-Standard 42-D-1984 R 1993 and ISO $9284 .^{25}$

\begin{tabular}{|c|c|c|c|c|c|c|c|c|c|}
\hline $\begin{array}{l}\text { Grain } \\
\text { short } \\
\text { name }\end{array}$ & $\begin{array}{l}\text { Mesh } \\
{[\mu \mathrm{m}]}\end{array}$ & $\begin{array}{c}\text { Residual } \\
\text { Mass } \\
\text { Q } 1 \\
\text { \% }\end{array}$ & $\begin{array}{r}\text { Mesh } \\
{[\mu \mathrm{m}]}\end{array}$ & $\begin{array}{c}\text { Residual } \\
\text { Mass } \\
\text { Q2 } \\
\%\end{array}$ & $\begin{array}{l}\text { Mesh } \\
{[\mu \mathrm{m}]}\end{array}$ & $\begin{array}{c}\text { Residual } \\
\text { Mass } \\
\text { Q2+ Q3 } \\
\text { \% }\end{array}$ & $\begin{array}{l}\text { Mesh } \\
{[\mu \mathrm{m}]}\end{array}$ & $\begin{array}{c}\text { Residual } \\
\text { Mass } \\
\text { Q2+ } \\
\text { Q3+ Q4 } \\
\%\end{array}$ & $\begin{array}{l}\text { Rest in } \\
\text { the } \\
\text { bottom } \\
\text { shell } \\
\text { Q5\% }\end{array}$ \\
\hline F80 & 215 & 25 & 180 & 40 & 150 & 65 & 125 & NA & 3 \\
\hline
\end{tabular}

Table 2

SiC grain size distribution for particles F320 according to FEPA-Standard 42-D-1984 R 1993 and ISO $8486 .^{26}$

\begin{tabular}{|c|c|c|c|}
\hline Grain short name & $\begin{array}{c}3 \% \text { max., } \\
\text { larger than, }[\mu \mathrm{m}]\end{array}$ & $\begin{array}{c}50 \% \text { min., } \\
\text { in size range, }[\mu \mathrm{m}]\end{array}$ & $\begin{array}{c}94 \% \text { min., } \\
\text { larger than, }[\mu \mathrm{m}]\end{array}$ \\
\hline F320 & 74.1 & $35.3-39.1$ & 17.1 \\
\hline
\end{tabular}

\subsection{Electrochemical measurements}

For both electrochemical and in-vitro immersion tests, the testing solution was simulated body fluid (SBF). ${ }^{27}$ (prepared using: $7.99 \mathrm{~g} \mathrm{~L}^{-1} \mathrm{HCl}, 0.35 \mathrm{~g} \mathrm{~L}^{-1} \mathrm{NaHCO}_{3}, 0.23 \mathrm{~g} \mathrm{~L}^{-1} \mathrm{KCl}, 0.23 \mathrm{~g} \mathrm{~L}^{-1}$ $\mathrm{K}_{2} \mathrm{PO}_{4} \cdot 3 \mathrm{H}_{2} \mathrm{O}, 0.30 \mathrm{~g} \mathrm{~L}^{-1} \mathrm{MgCl}_{2} \cdot 6 \mathrm{H}_{2} \mathrm{O}, 0.36 \mathrm{~g} \mathrm{~L}^{-1} \mathrm{CaCl}_{2} \cdot 2 \mathrm{H}_{2} \mathrm{O}, \mathrm{g} \mathrm{L}^{-1} 0.07 \mathrm{Na}_{2} \mathrm{SO}_{4}$, buffering at $\mathrm{pH} 7.4$ with tris(hydroxymethyl)aminomethane $\left(\left(\mathrm{HOCH}_{2}\right)_{3} \mathrm{CNH}_{2}\right)$ and $\mathrm{HCl}$. The tests were carried out at $37 \pm 0.5^{\circ} \mathrm{C}$ according to ASTM-G31-72. ${ }^{28}$ An O-ring cell with an exposed area of $0.78 \mathrm{~cm}^{2}$ was used in polarization tests and electrochemical impedance spectroscopy (EIS). A conventional three-electrode system was used for the measurements, where samples fixed 
on the O-ring cell served as working electrode, a Pt foil served as counter electrode, and $\mathrm{Ag} / \mathrm{AgCl}\left(3 \mathrm{~mol} \mathrm{dm}^{-3} \mathrm{KCl}\right)$ was applied as reference electrode. After the O-ring cell was filled with $50 \mathrm{ml}$ SBF solution, the testing sample was immersed for 1 hour to reach a stable condition before further electrochemical tests. Potentiodynamic polarization curves were measured with the potential scanning rate of $3 \mathrm{mV} \mathrm{s}^{-1}$ from $-1 \mathrm{~V}$ to $0 \mathrm{~V}$. For long-time electrochemical impedance spectroscopy (EIS) measurement, the testing sample was mounted on the O-ring cell and the measurement was conducted in certain time points (day $0,1,3,7$, $14,21,28)$. The amplitude of the signal was $10 \mathrm{mV}$ in the frequency range from $100 \mathrm{kHz}$ to $10 \mathrm{mHz}$ for impedance data acquisition. For the long-term experiments the SBF solution was replaced every 7 days.

\subsection{In-vitro immersion test}

The in-vitro immersion test was carried out to investigate the degradation behavior, including corrosion morphology, surface composition, and weight loss. Testing samples were separately immersed in $65 \mathrm{ml}$ SBF solution, which was refreshed every 7 days. After immersion for 4 weeks, samples were rinsed by deionized water and ethanol, and dried in nitrogen for characterizing surface morphology and composition. To measure the weight loss and the more detailed morphology of the substrate after immersion, samples were ultra-sonicated cleaned in acetone for 1 hour to remove corrosion product layer, then weighted by a balance and SEM pictures were taken.

The cleaning method used in this work prevents the substrate from being corroded during the cleaning procedure by, for example, physical scratching or chemical corrosion. But it should be pointed out that the corrosion product layer is hard to be completely removed by this method. Nevertheless, compared to sandblasted surface, it is easier to remove the degradation layers on the flat surface by ultra-sonication cleaning. Therefore, the true weight- 
loss difference between the untreated and the sandblasted samples is somewhat larger than here reported.

\subsection{Surface morphology and composition}

The surface and cross-section morphology of samples after sandblasting and the in-vitro immersion test was observed using a scanning electronic microscope (SEM, Hitachi FE-SEM S4800). The contact angle of the bare iron, F320 sample, and F80 sample was measured with a Drop Shape Analyzer KRÜSS DSA30, and the volume of each drop of distilled water was 3 $\mu \mathrm{L}$. After immersion, the degradation products were analyzed by Fourier Transform Infrared Spectroscopy (FTIR), and energy dispersive X-ray (EDX). The chemical composition of surfaces was determined by an X-ray photoelectron spectrometer (XPS, PHI 5600 XPS spectrometer, USA). XPS spectra were acquired using Al standard X-rays with a pass energy of $23.5 \mathrm{eV}$. All XPS element peaks were shifted to a C1s standard position (284.8eV). No clear peaks could be observed in X-ray diffractometer (XRD), indicating that most of the degradation products are amorphous.

\subsection{Cytocompatibility studies}

Human osteoblast-like cells (MG-63) (ATCC®, Sigma-Aldrich) were used for cytocompatibility studies. Cells were cultured in Dulbecco's modified Eagle‘s medium (DMEM, Gibco®, Germany) supplemented with 10 vol. \% fetal bovine serum (FBS, SigmaAldrich) and 1 vol. \% penicillin/streptomycin (PS, Sigma-Aldrich), at $37^{\circ} \mathrm{C}$ in a humidified atmosphere of $95 \%$ air and $5 \% \mathrm{CO}_{2}$. Cells were grown for $48 \mathrm{~h}$ to confluence in $75 \mathrm{~cm}^{2}$ culture flasks (Greiner-Bio One), washed with phosphate buffer solution (PBS), detached using Trypsin-EDTA (Sigma), and counted by a hemocytometer (Roth). Afterwards, samples were either incubated directly or indirectly with the MG-63 cells. 


\subsubsection{Cell viability}

Cell viability of sandblasted samples and the bare iron in extraction medium was investigated by the WST-8 assay (Sigma Aldrich). Extraction media were collected from 2 days immersion solution of sandblasted samples and the bare iron in DMEM. $0.5 \mathrm{~mL}$ of extraction medium was inject into one well of 24 well-plates along with $0.5 \mathrm{~mL}$ of DMEM containing 50000 cells. After $48 \mathrm{~h}$ of cultivation, the culture medium was removed from the incubated plates, which were subsequently washed with PBS. Then, DMEM containing 1\% (v/v) WST-8 assay reagent was added into wells and incubated for $2 \mathrm{~h}$. Afterwards, $100 \mu \mathrm{L}$ of supernatant from each sample was transferred into a well of a 96-well plate, and the absorbance of the liquid was measured with a micro-plate reader (PHOmo, autobio labtec instruments co. Ltd.) at $450 \mathrm{~nm}$. The relative absorbance ratio was calculated, which was compared with the control group (only containing MG-63 osteoblast-like cells).

\subsubsection{Cell morphology and cell counts}

To study the expressed cell morphology of MG-63 cells on surfaces of sandblasted samples and also the bare iron fluorescence imaging were carried out. MG-63 cells were seeded onto testing samples, which were previously sterilized by dry heat sterilization $\left(160^{\circ} \mathrm{C}, 2 \mathrm{~h}\right)$, at a density of $10^{5}$ cells well ${ }^{-1}$ in 24 well-plates, and incubated at $37{ }^{\circ} \mathrm{C}$ in a humidified atmosphere of $5 \% \mathrm{CO}_{2}$ for $48 \mathrm{~h}$. Afterwards, live staining was carried out with calcein acetoxymethyl ester (Calcein AM, Invitrogen, USA) for 45 minutes incubation. Fluorescence microscope (FM) (Axio Scope A.1, Carl Zeiss Microimaging GmbH, Germany) was used to image the calcein stained cells. Additionally, cell counts on the samples were performed on fluorescent images by using ImageJ software.

\section{Results and discussion}




\subsection{Surface microstructure and composition of sandblasted surfaces}

Average $\left(R_{a}\right)$ and maximal $\left(R_{\max }\right)$ surface roughness of bare iron, F320 and F80 samples were measured and results are presented in Fig. $1 . R_{a}$ and $R_{\max }$ of bare iron after polishing is $0.43 \pm$ $0.03 \mu \mathrm{m}$ and $1.2 \pm 0.12 \mu \mathrm{m}$, respectively. It can be clearly seen that both $\mathrm{R}_{\mathrm{a}}$ and $\mathrm{R}_{\max }$ of $\mathrm{F} 320$ sample $(0.97 \pm 0.05 \mu \mathrm{m}$ and $10.11 \pm 3.42 \mu \mathrm{m}$, respectively) are increased by the sandblasting treatment and both values significantly rise when the size of sandblasting particle changes from $\mathrm{F} 320$ to $\mathrm{F} 80(3.52 \pm 0.06 \mu \mathrm{m}$ and $36.38 \pm 4.76 \mu \mathrm{m}$, respectively).

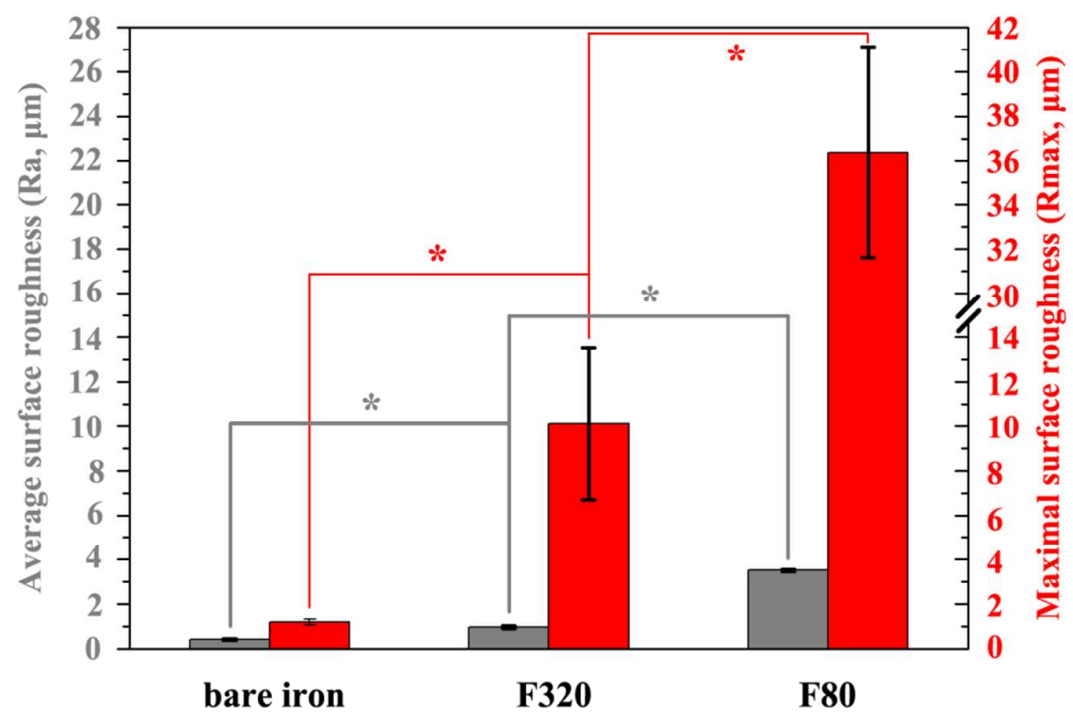

Fig. 1. Average $\left(\mathrm{R}_{\mathrm{a}}\right)$ and maximal $\left(\mathrm{R}_{\max }\right)$ surface roughness of the bare iron, $\mathrm{F} 320$ and $\mathrm{F} 80$ samples (mean \pm standard deviation $)$, and statistically significant difference is signed by $*(\mathrm{P}<$

Besides the surface roughness, samples show notable differences in the surface microstructure and composition after the sandblasting treatment (Fig. 2). Cracks can be found spreading over both F320 and F80 samples, while the roughness of F80 sample is significantly higher than that of F320 sample. From the cross-section it can be seen that the 
rough surface of F320 sample is composed of small cracks. For the F80 sample, it is composed of cracks and cavities with a more irregular structure, and some cracks develop vertically and deeply into the substrate. The contact angle of F320 sample is $100.7 \pm 0.4$, whereas that of F80 sample is $109.6 \pm 0.9$. Due to the high surface roughness, both sandblasted surfaces show hydrophobicity.

In the EDX test, only iron and silicon signals can be detected from the sandblasted surface; the atomic percentage of element silicon is $10.12 \%$ for F320 sample and $7.52 \%$ for F80 sample. The presence of $\mathrm{Si}$ indicates that some $\mathrm{SiC}$ particles are imbedded into the substrate. The lower SiC content in the surface of F80 sample could due to the bigger size of F80 SiC particles, rendering it more difficult to intrude through the surface of substrate.

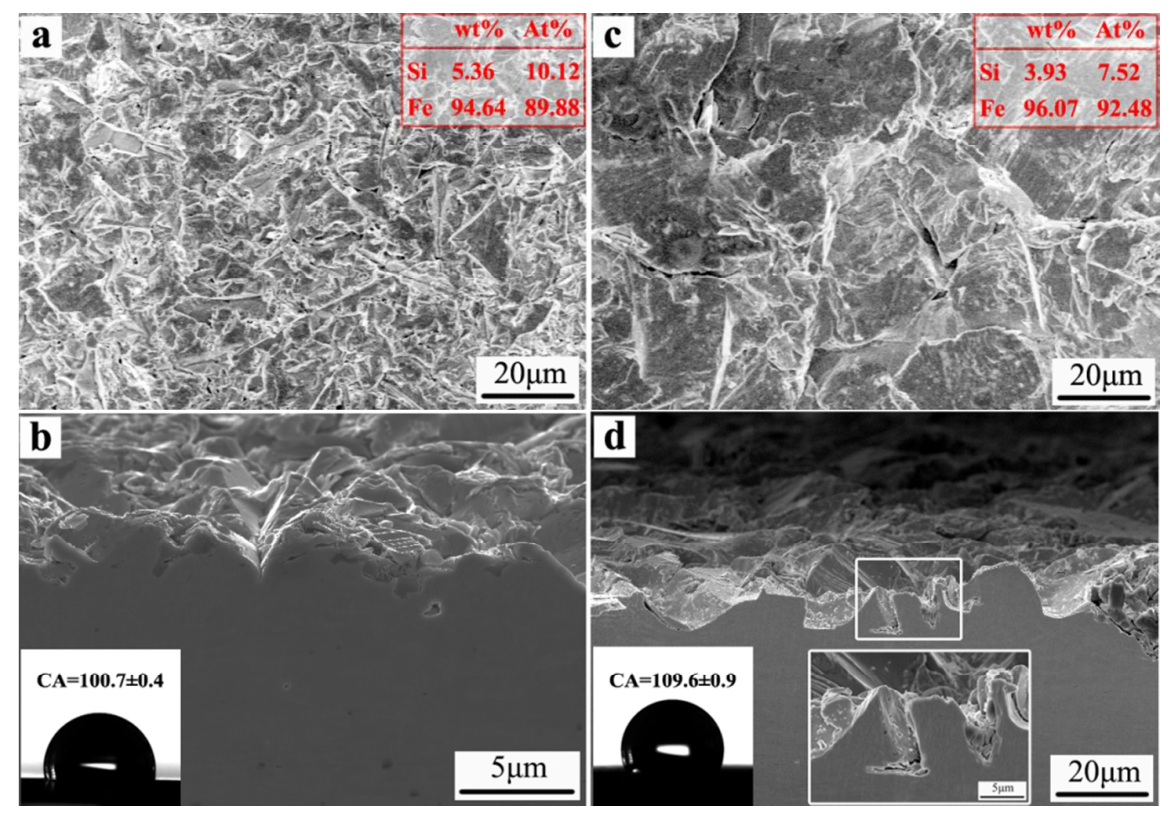

Fig. 2. (a,c) Surface morphology, EDX analysis results, and (b,d) cross-section morphology of F320 sample and F80 sample; insets show the contact angle (CA) of F320 sample and F80 sample. 
Galvanic corrosion of metal/SiC-based ceramic coupling has been investigated before. ${ }^{29}$ $\mathrm{SiC}$ represents the cathodic site of the couple and the galvanic corrosion is limited, since the area ratio metal/SiC is very high (the area rule). Moreover, once the $\mathrm{SiC}$ particle is covered by the corrosion product, the effect caused by galvanic corrosion is expected to be negligible. Biocompatibility of SiC particles has been studied before, it has been reported that no obvious cytotoxicity can be found..$^{30,31}$
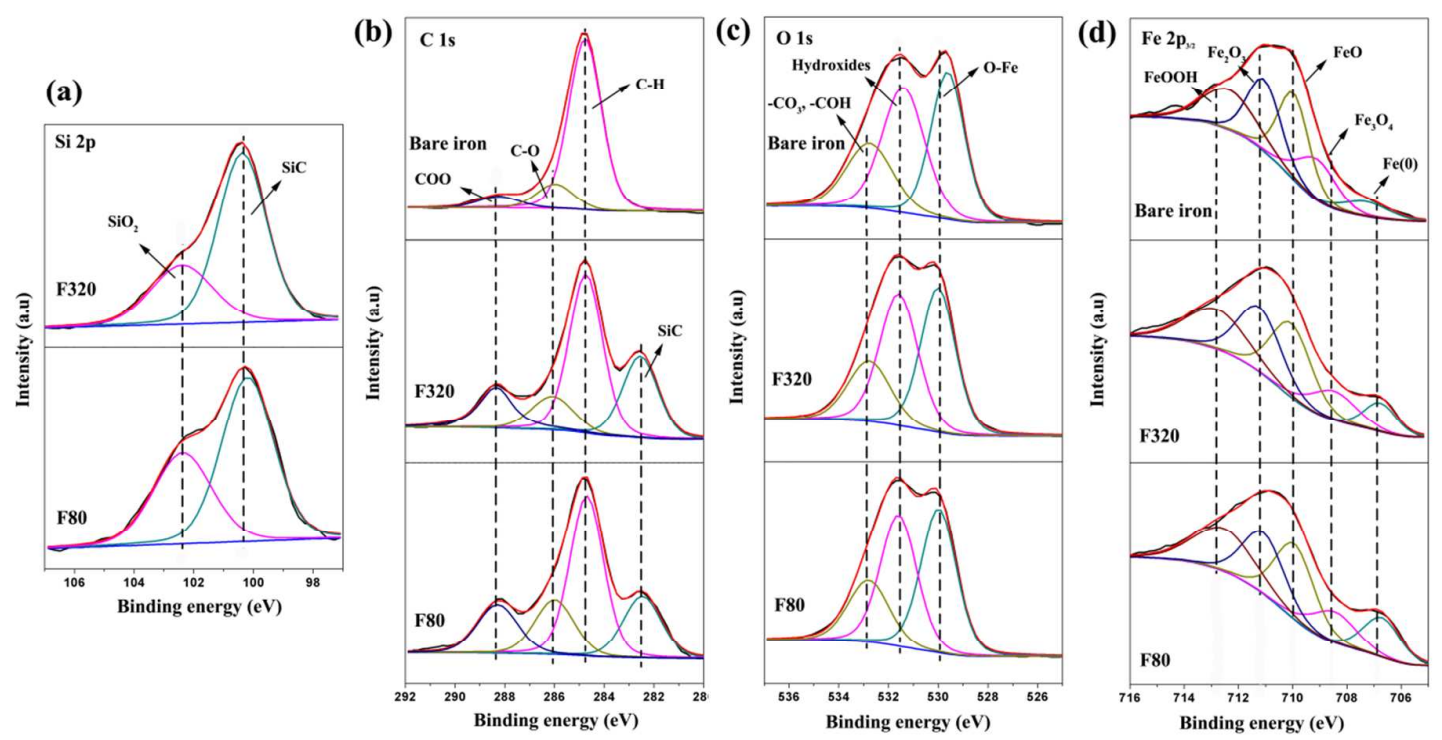

Fig. 3. High-resolution XPS (a) Si 2p, (b) C 1s, (c) O 1s, and (d) Fe 2p $p_{3 / 2}$ spectra of the sample surfaces.

To further investigate the composition and element valence states of the sample surfaces, XPS analysis is included. XPS results show that the outermost layers mainly contain $\mathrm{C}, \mathrm{O}$, and Fe for all samples, and Si can only be observed on F320 and F80 samples (Fig. 3). In accordance with EDX results, the signal from silicon is detected with peaks at $100.2 \mathrm{eV}$ for $\mathrm{SiC}$ and $102.5 \mathrm{eV}$ for $\mathrm{SiO}_{2}$ (Fig. 3a). ${ }^{32}$ The spectra of C 1s (as shown in Fig. 3b) of F320 and F80 samples also show the peak at $282.5 \mathrm{eV}$ which can be assigned to SiC. Other three peaks at about $284.9 \mathrm{eV}, 286.1 \mathrm{eV}$, and $288.3 \mathrm{eV}$ can be assigned for $\mathrm{C}-\mathrm{H}, \mathrm{C}-\mathrm{O}$, and $\mathrm{COO}$ 
species, respectively. ${ }^{33}$ For the bare iron and sandblasted samples, three peaks at about 529.6 $-530.0 \mathrm{eV}, 531.5 \mathrm{eV}$, and $532.8 \mathrm{eV}$ are fitted after deconvolution of the $\mathrm{O} 1 \mathrm{~s}$ signal (Fig. 3c). The first peak indicates the existence of iron oxide and the second peak can be assigned to hydroxides. ${ }^{34}$ The last peak can be derived from the organic oxygen impurities. ${ }^{35}$ Fig. $3 \mathrm{~d}$ shows Fe $2 \mathrm{p}_{3 / 2}$ signal which is fitted with five peaks at $706.7 \mathrm{eV}$ for metallic Fe, $708.4-709.0$ $\mathrm{eV}$ for $\mathrm{Fe}_{3} \mathrm{O}_{4}, 709.9 \mathrm{eV}$ for $\mathrm{FeO}, 711.1 \mathrm{eV}$ for $\mathrm{Fe}_{2} \mathrm{O}_{3}$, and $712.4-712.8 \mathrm{eV}$ for $\mathrm{FeOOH}{ }^{36}$

Native, air-formed oxide films on both bare iron and sandblasted samples are complex and thin; thickness being in the nm-range (hence, they cannot be observed in SEM images or detected in XRD measurements). No significant difference can be found on the surface composition between the pure iron and sandblasted samples, except the existence of SiC on sandblasted samples. Notably, more signals from metallic Fe can be detected on sandblasted samples. This could be due the cracks on the surface, as the substrate inside deep cracks may be only covered by extremely thin oxidization layers, so that more metallic Fe under these layers can be detected.

\subsection{Electrochemical measurements}

Fig. 4 presents the EIS plots (Nyquist, Bode, and phase angle) of samples after immersion in SBF solution for 1 hour. Results indicate almost no difference in the corrosion behavior of all samples in this initial state. In all cases, one capacitive loop is observed, indicating a similar corrosion mechanism for all samples. The slight shift in the phase angle between the bare iron and the sand-blasted samples is most probably due to larger surface area of the rough surfaces, shifting the interfacial capacitance. 
(a)

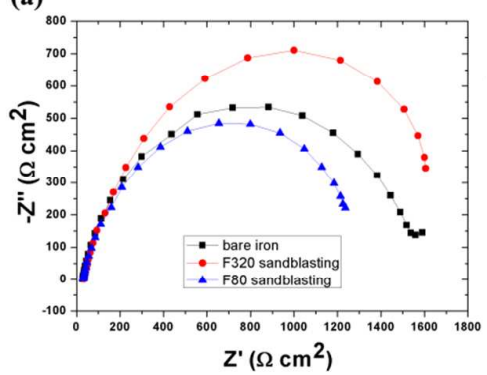

(b)

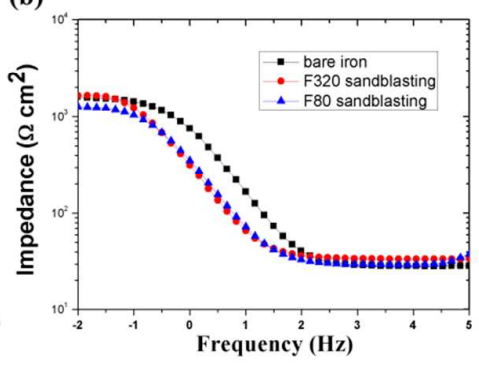

(c)

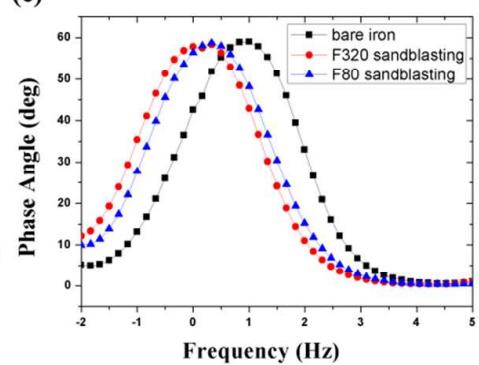

Fig. 4. (a) Nyquist, (b) Bode impedance (c) and phase angle plots of different samples at $\mathrm{E}_{\text {corr }}$ in SBF (after immersion in SBF solution for $1 \mathrm{~h}, \mathrm{E}_{\text {corr }}$ of all sample is around $-0.67 \mathrm{v}$ ).

Potentiodynamic polarization curves of the samples are shown in Fig. 5. There is a distinct passivation region in the anodic curve of bare iron, indicated by the decrease of the current density in the potential range from around $-0.55 \mathrm{~V}$ to $-0.38 \mathrm{~V}$. In the case of sandblasted samples, their cathodic current density is slightly higher than that of the bare iron. In analogy to the bare iron sample, the anodic current density also starts to decrease at around $-0.55 \mathrm{~V}$ for the sandblasted samples. The passivation regions of the sandblasted samples are, however, much smaller than that of the bare iron. The F80 sample shows even smaller passivation region compared to the F320 sample.

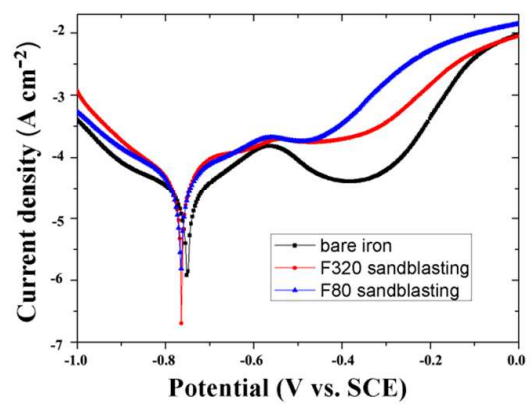

Fig. 5. Polarization curves of different samples in SBF.

The higher cathodic current density of the sandblasted samples is attributed to their relatively larger surface area. The large surface area could also increase the anodic current 
density of sandblasted samples. However, the difference in the passivation region is significantly larger than in the cathodic region, indicating that there are other influencing factors besides the surface area. The small passivation region of the sandblasted samples indicates a deleterious effect of this surface treatment for formation of protective surface layers (note: for iron-based biodegradable implants, passivation of the surface is not desired).

(1)
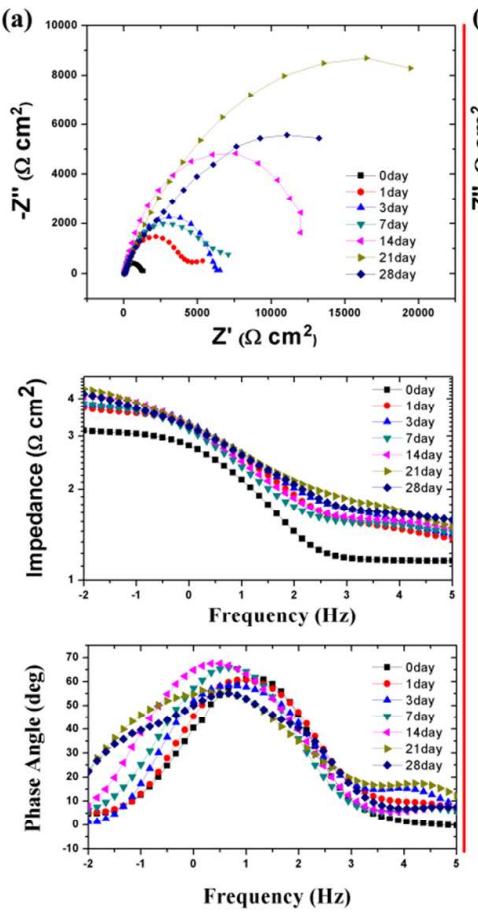
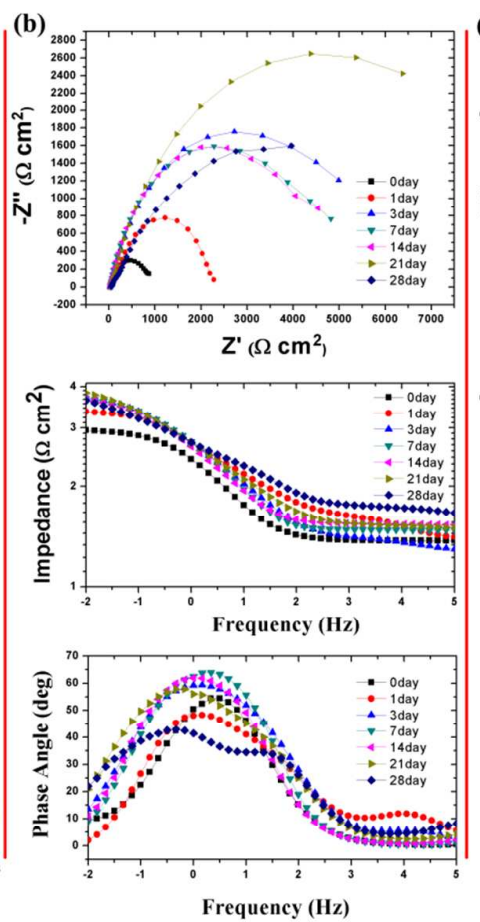
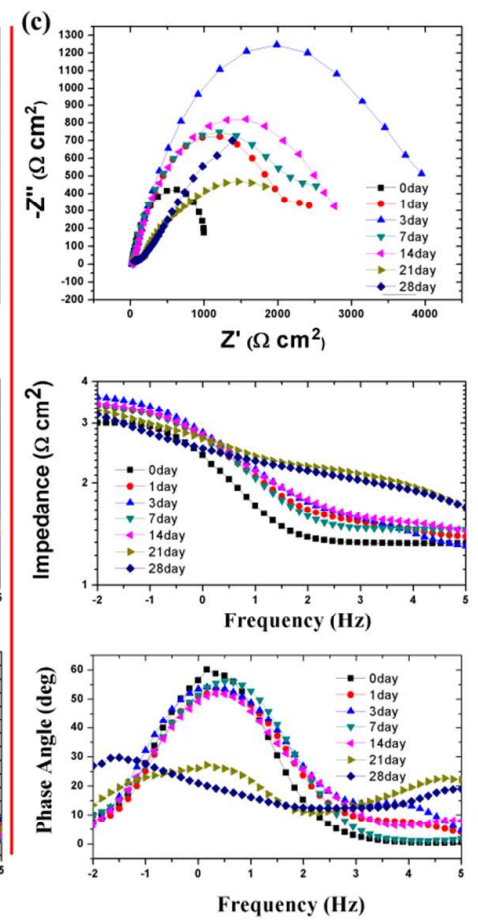

Fig. 6. Nyquist, Bode impedance, and phase angle plots (from above down) of (a) bare iron, (b) F320 sample, and (c) F80 sample in the long-term EIS measurement.

Fig. 6 and Fig. 7 show the EIS results and the low-frequency impedance value as a function of time during 28 days. From day 0 to 3 , the impedance value of all samples increases with immersion time, indicating that a partially protective corrosion product layer is growing on all samples increasing the corrosion resistance in this period. From day 3 to 28 , samples with different surface treatments show significantly different electrochemical behavior. The impedance value of the bare iron keeps increasing until day 21 , then decreasing at day 28 . On 
the contrary, the impedance values of sandblasted samples, which are significantly lower than that of the bare iron, remain in a small range of variation after day 3. Notably, different from the bare iron and F320 sample, the phase angle of F80 sample in low frequency does not increase during day 0 to 14 . Moreover, the Nyquist plot and phase angle at day 21 and 28 indicate a change in the degradation mechanism of the F80 sample.

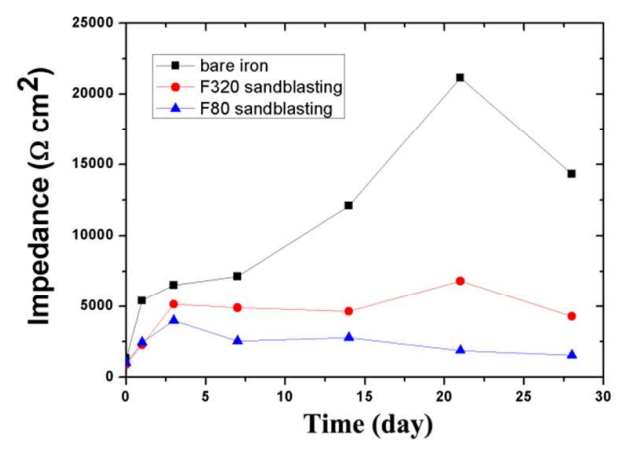

Fig. 7. The low-frequency impedance value $\left(\mathrm{R}_{10 \mathrm{mHz}}\right)$ of different samples as a function of immersion time in the long-term EIS measurement (the impedance value collected at $10 \mathrm{mHz}$ of each time point was presented).

In each time point, the bare iron has the highest low-frequency impedance value corresponding to the lowest corrosion rate. The flat and smooth interface can endow good adhesion between the corrosion product layer and the iron substrate, enabling a better protection to the substrate when the corrosion product layer keeps growing. Upon longer immersion time, the occurrence of localized corrosion and breakdown of protective layers can reduce the corrosion resistance, leading to relatively low impedance of the bare iron at day 28 .

After day 3, no notable increment of impedance can be found on the sandblasted samples, even though there were also corrosion product layers forming on surfaces. Because of the sandblasting treatment, the substrate underneath the corrosion product layers presents high electrochemical activity and formation of uniform, protective corrosion product layers seems 
to be hampered on the rough surfaces. Especially, for F80 sample immersed for over 21 days, the corrosion mechanism changed from charge-controlled to diffusion-controlled, as indicated by the shape of the EIS spectra. This indicates a high rate of the charge-transfer controlled Fe oxidation reaction (anodic reaction), the corrosion rate therefore being controlled by the slow oxygen diffusion to the surface (cathodic reaction being oxygen reduction). For the other samples the anodic reaction is slower, due to the formation of more protective corrosion product layers; hence the reaction rate remains under charge-transfer control.

\subsection{Long-term immersion test}

Samples immersed for 28 days were characterized by FTIR and EDX to analyze their degradation products. In the FTIR spectra of all three samples (Fig. 8), the broad band observed in the range $3700-3000 \mathrm{~cm}^{-1}$ is assigned to adsorbed water. ${ }^{37}$ Bands at 1630 and $1000 \mathrm{~cm}^{-1}$ are due to the presence of iron phosphate. ${ }^{37,38}$ Especially, for sandblasted samples, there is a peak at $2880 \mathrm{~cm}^{-1}$ which is attributed to silicon carbide. Typical corrosion product layers of iron are composed of iron oxides and hydroxides $;{ }^{39}$ however, in this case no clear signals derived from these species can be distinguished.

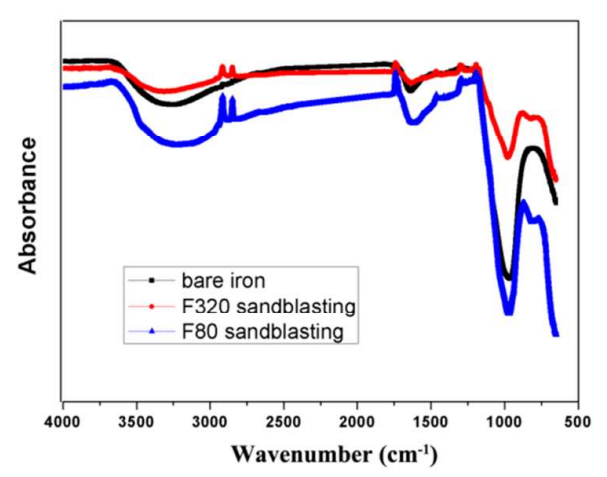

Fig. 8. FTIR analyses of different samples after immersion in SBF for 28 days (The peaks of interest are discussed in the text). 
All samples after immersion are covered by corrosion product layers, and show a similar surface morphology which is rough and loose (Fig. 9). From the EDX data, the relatively high amount of phosphorus indicates the presence of iron phosphate in corrosion products. The element silicon is only found in F320 sample. This could be due to the fact that silicon carbide particles were embedded into the rough surface of F80 sample and become covered by thick corrosion product layers.
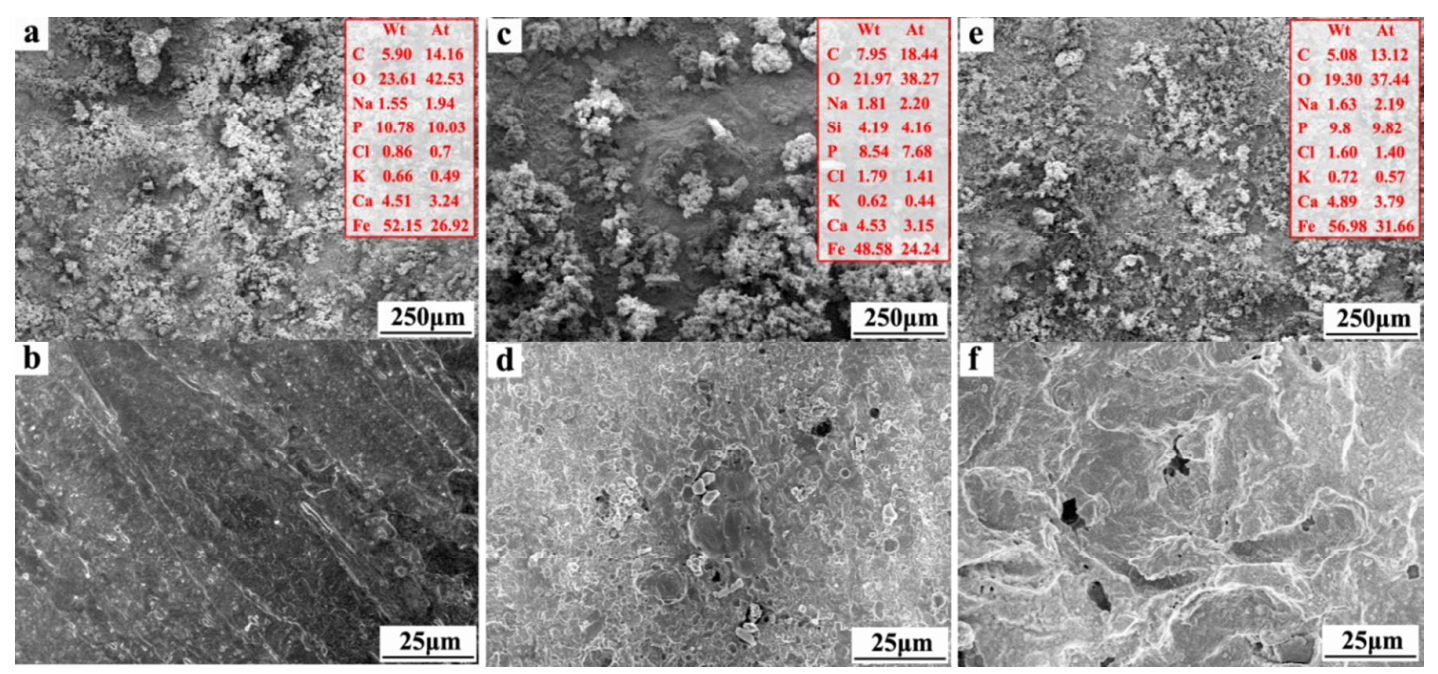

Fig. 9. Surface morphology $(a, c, e)$ before and $(b, d, f)$ after removing the corrosion products of the bare iron, F320 sample, and F80 sample; the EDX analyses of the corrosion products of each sample are also presented in (a,c,e).

Corrosion product layers were removed by ultra-sonication treatment, in order to observe the morphology of the corroded substrates (Fig. 9 b,d,f). The bare iron shows a relatively flat surface and no obvious localized corrosion can be found, indicating a rather uniform degradation behavior. Compared to the bare iron, substrates of sandblasted samples are significantly rougher (in accordance with the initial surface roughness, see Fig. 1). The surface of F320 sample presents a porous structure, consisting of many protrusions and 
cavities. The F80 sample shows a similar porous structure with even higher roughness and larger cavities.

During the sandblasting treatment, the dislocation density of the surface increases and numerous defects are generated on the surface, which could induce localized degradation behavior. Compared to Fig. 2, cavities on the surface are extended, indicating that the degradation rate is faster in regions around cracks and cavities.

Fig. 10 shows cross-sections of all samples after immersion without ultra-sonication treatment. For the bare iron, the boundary of the substrate is relatively flat and no obvious localized corrosion is found. For sandblasted samples, uneven boundaries can be seen on both two samples. The high surface roughness makes it inappropriate to measure the average thickness of the corrosion product layers on the sandblasted samples. Nevertheless, the thickness of the corrosion product layers on the sandblasted samples is clearly higher than that on the bare iron. 
1

2

3

4

5

6

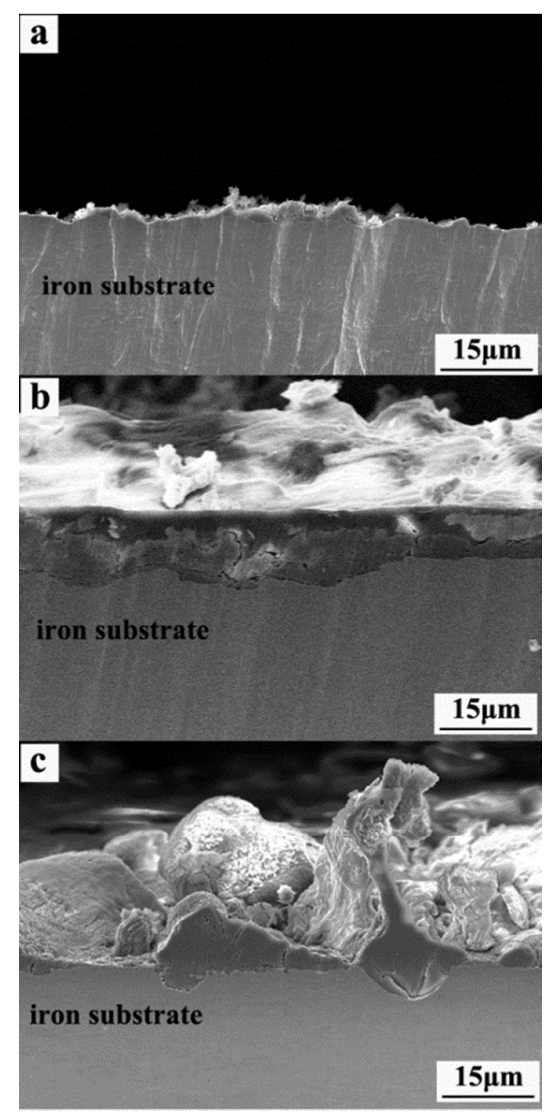

Fig. 10. Cross-section morphology of (a) the bare iron, (b) the F320 sample, and (c) the F80 sample after immersion in SBF for 28 days.

On the one hand, thick corrosion product layers reveal that more substrate is converted into oxidation layers (i.e., a higher corrosion rate of the metallic substrate). This indicates that the substrate is activated by the sandblasting treatment. On the other hand, the thick corrosion product layers are much less protective than the thinner layer on bare iron (results in Fig. 7). Hence, the sand-blasting treatment is able to prevent the formation of highly protective corrosion product layers on $\mathrm{Fe}$ in phosphate-containing simulated body solution - which is a generally acknowledged challenge for biodegradation of Fe. Even though the substrates of sandblasted samples show uneven attack morphology, no localized corrosion developed deeply in the vertical direction. Therefore it can be expected that the influence of sandblasting 
on the mechanical integrity is limited. The mechanical performance of sandblasted samples during immersion will be investigated in future work.

The weight loss of samples after 28 days immersion in SBF is presented in Fig. 11. It is clear that the bare iron shows the lowest value and there is significant difference between the bare iron and sandblasted samples $(\mathrm{p}<0.05)$. Even though the results show no significant difference between the F320 and F80 samples ( $p>0.05$ ), the F80 sample still shows slightly higher value.

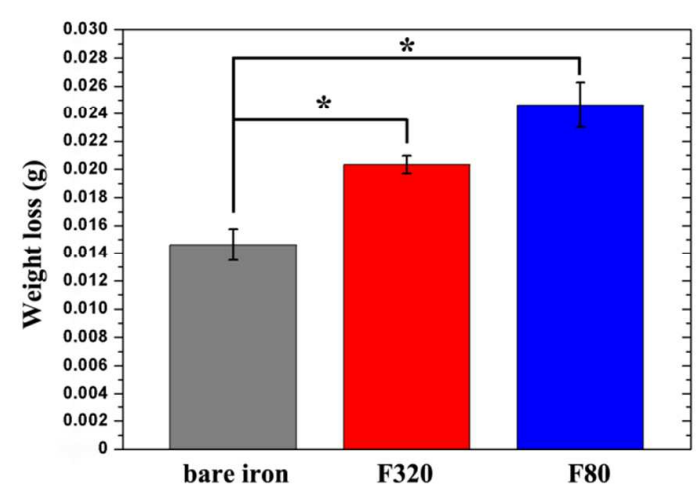

Fig. 11. Weight loss of different samples after immersion in SBF for 28 days (mean \pm standard deviation), and statistically significant difference is signed by $*(\mathrm{P}<0.05)$

The high weight loss of sandblasted samples could be attributed to three reasons, the change of surface composition, surface area, and surface morphology. After sandblasting treatment, the embedded $\mathrm{SiC}$ particles on the surface could cause micro-galvanic corrosion. This influence of the change of surface composition is, however, limited and is expected to vanish soon after immersion in solution. The rougher surface of sandblasted samples exposes more surface area to the immersion solution. This should be a key factor in the degradation process during the initial immersion period. Afterwards, the substrate is covered by degradation products, and the activity of the substrate is strongly influencing the degradation 
process. In the case of bare iron, the flat interface leads to a good adhesion between the substrate and the degradation product layer, so that the degradation product layer can provide sufficient corrosion resistance to the substrate of bare iron. In addition, the flat surface is relatively inactive compared to sandblasted surface, which is illustrated by the electrochemical measurements. On the contrary, the degradation product layer on the sandblasted surfaces can only offer limited protection. Underneath the degradation product layer, cracks with the irregular shape offer access to the electrolyte and space to the propagation of degradation. In addition, the sandblasting treatment introduces a high dislocation density and high residual stress on the surface, these factors also increase the activity of the substrate.

\subsection{Evaluation of cytocompatibility}

The evaluation of relative cell behavior is a conventional test to estimate the biological safety of materials. Since the ferric ion from samples could bring significant effect to the WST-8 dye, an indirect contact method was employed in this work. Fig. 12 presents results of the WST-8 assay, from which can be seen that the ratio of extraction media groups is slightly lower compared to the control group, and the statistically significant difference can be found between sandblasted samples and the control group.

In the WST-8 assay, the formazan is generated from the cleavage of WST only by viable cells. Even though Fe is considered as an essential element for human body, it has been reported that the cell damage caused by different forms of Fe. ${ }^{40,41}$ Results from the WST-8 assay shows difference between sandblasted samples and the control group. Nevertheless, all the ratio of extraction media groups is above 0.9 , indicating the good cytocompatibility of extraction media and the limited cytotoxicity of degradation products. For the indirect contact assay, cells only interact with extraction media and the potential cytotoxicity could only be 
derived from degradation products of materials. To further investigate the cytocompatibility of sandblasting surfaces, fluorescent images of cells on samples were taken.

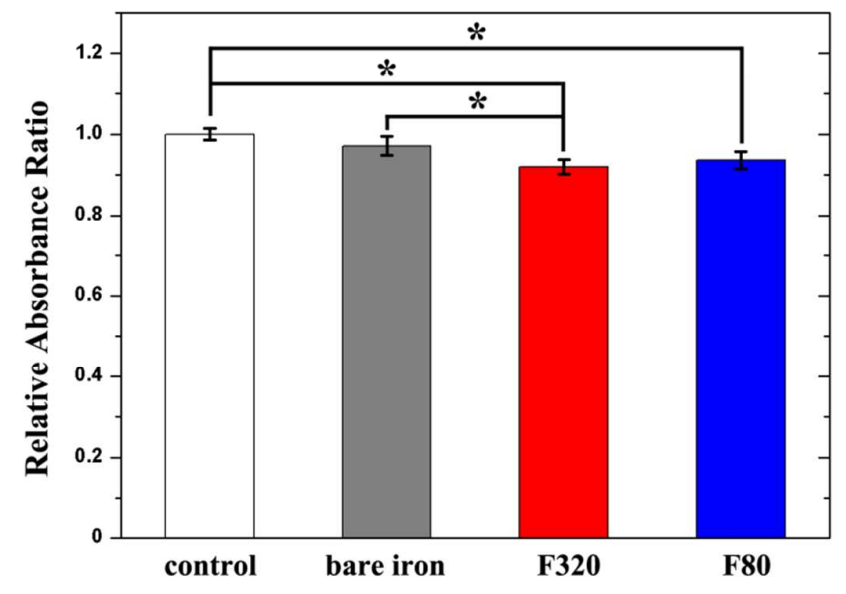

Fig. 12. The relative absorbance ratio of the bare iron, F320 sample, and F80 sample in WST assay (mean \pm standard deviation) compared to the control group, and statistically significant difference is signed by $*(\mathrm{P}<0.05)$.

Representative fluorescent images of stained human osteoblast-like cells (MG-63) after 48 h culture are shown in Fig. 13. After 2 days of incubation, it can be seen that MG-63 cells proliferated and adhered over surfaces of all three samples. From these images, one can see that the spreading behavior of cells on all samples was inhibited. Some of the cells on all samples showed round-shape morphology and only some cells were connected with each other. No significant difference was found in cell counts on different samples and the range of average value is from 360 to 430 cells $\mathrm{mm}^{-2}$. Especially, for fluorescent images of sandblasted samples, some areas were out of focus because of the high roughness. 

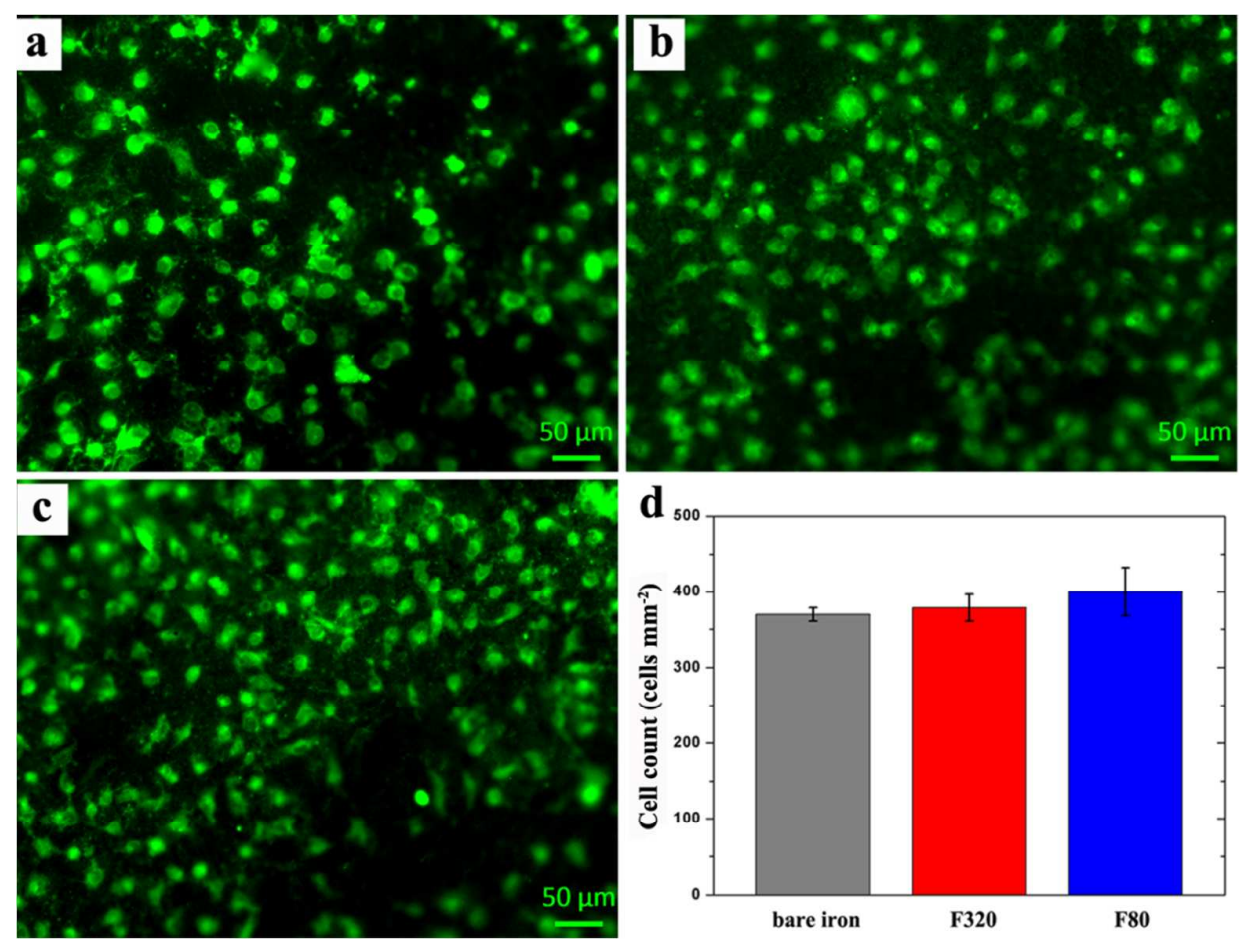

Fig. 13. Representative fluorescent images of stained human osteoblast-like cells (MG-63) after $48 \mathrm{~h}$ culture on (a) the bare iron, (b) F320 sample, and (c) F80 sample; (d) cell counting from fluorescent images after $48 \mathrm{~h}$ culture.

The cytocompatibility of a given material is closely associated with the cells' behavior on the surface of this material, which is directly responded to the substrate topography. ${ }^{21,42}$ Certain cell types show a preference for surface with different roughness. ${ }^{43}$ Studies on hydroxyapatite,${ }^{44}$ titanium-based implants,${ }^{45}$ and Fe-Pd based alloys ${ }^{46}$ showed that the adhesion and proliferation of osteoblasts, which is crucial for the osseointegration, are improved by the rough surface. It is also observed that osteoblastic cells prefer rougher surfaces, whereas smooth surfaces are better for the proliferation of fibroblasts cells on highpurity aluminum sheets. ${ }^{21}$

In this work, human osteoblast-like cells (MG-63) were studied on surfaces with two roughness types, which were fabricated by sandblasting treatment using F80 and F320 SiC 
particles. Results show a similar trend as the indirect contact assay (WST-8 assay). It can be confirmed from the morphology of cells that the activity of living cells on sandblasted surfaces is not influenced by the surface roughness for the investigated surfaces. MG-63 cells distribute well on sandblasted surfaces and show similar morphology as on the flat bare substrate. However, the round-shape morphology of cells on all samples indicates that the growth of cells is not in the ideal condition. Nevertheless, it is clear that no additional adverse effect on the cell behavior has been caused by the sandblasting treatment.

The sandblasting treatment could be applied to both the iron-based coronary stent and the iron-based bone implant. For the coronary stent, restenosis and thrombosis are potential clinical issues and they could be influenced by the surface roughness. Therefore, in our future studies, investigation related to thrombosis should be accomplished and the cytotoxicity of the sandblasted sample should be further evaluated by endothelial cells. Finally, in vivo tests would be required to investigate biodegradation and tissue response in terms of the iron-based bone implant.

\section{Conclusions}

The corrosion behavior and biocompatibility of biodegradable pure iron treated by sandblasting were investigated. After the sandblasting treatment, the flat surface turns into a rough surface with cracks. Electrochemical tests reveal that sandblasted samples have low corrosion resistance in simulated body fluid, which becomes even more noteworthy in longterm immersion tests: here formation of a highly protective corrosion product layer - as takes place on bare iron - is hindered. Weight loss measurement further confirmed that the degradation rate of sandblasted samples is significantly higher than that of the bare iron. This result could be attributed to the surface properties of sandblasted samples including the change of surface composition (for the early stage), high roughness, and the high dislocation 
density (high residual stress). In cell cytocompatibility studies, both the indirect and direct contact methods demonstrate that sandblasting brings no adverse effect to the growth of human osteoblast-like cells (MG-63). Sandblasting hence is demonstrated to be an effective way to increase the degradation rate of pure iron without compromising the cytocompatibility. Therefore, sandblasting could serve as a suitable pretreatment for subsequent surface functionalization to further control the degradation behavior and biocompatibility of ironbased implants.

\section{Acknowledgements}

Juncen Zhou (No. 201406990028) and Yuyun Yang (No. 201308230074) gratefully acknowledge the China Scholarship Council (CSC) for financial support.

\section{Reference}

(1) Witte, F. The History of Biodegradable Magnesium Implants: A Review $\_$. Acta Biomater. 2010, 6 (5), 1680-1692.

(2) Schinhammer, M.; Hänzi, A. C.; Löffler, J. F.; Uggowitzer, P. J. Design Strategy for Biodegradable Fe-Based Alloys for Medical Applications. Acta Biomater. 2010, 6 (5), 1705-1713.

(3) Niinomi, M.; Nakai, M.; Hieda, J. Development of New Metallic Alloys for Biomedical Applications. Acta Biomater. 2012, 8 (11), 3888-3903.

(4) Zhu, S.; Huang, N.; Xu, L.; Zhang, Y.; Liu, H.; Sun, H.; Leng, Y. Biocompatibility of Pure Iron: In Vitro Assessment of Degradation Kinetics and Cytotoxicity on Endothelial Cells. Mater. Sci. Eng., C 2009, 29 (5), 1589-1592.

(5) Choudhary, L.; Raman, R. K. S. Magnesium Alloys as Body Implants: Fracture Mechanism under Dynamic and Static Loadings in a Physiological Environment. Acta Biomater. 2012, 8 (2), 916-923.

(6) Kuhlmann, J.; Bartsch, I.; Willbold, E.; Schuchardt, S.; Holz, O.; Hort, N.; Höche, D.; Heineman, W. R.; Witte, F. Fast Escape of Hydrogen from Gas Cavities around Corroding Magnesium Implants. Acta Biomater. 2013, 9 (10), 8714-8721.

(7) Chen, Y.; Zhao, S.; Liu, B.; Chen, M.; Mao, J.; He, H.; Zhao, Y.; Huang, N.; Wan, G. Corrosion-Controlling and Osteo-Compatible Mg Ion-Integrated Phytic Acid (Mg-PA) 
Coating on Magnesium Substrate for Biodegradable Implants Application. ACS Appl. Mater. Interfaces 2014, 6, 19531-19543.

(8) Hornberger, H.; Virtanen, S.; Boccaccini, a. R. Biomedical Coatings on Magnesium Alloys - A Review. Acta Biomater. 2012, 8 (7), 2442-2455.

(9) Taggart, D. P. Coronary-Artery Stents. N. Engl. J. Med. 2006, 354, 2076-2078; author reply $2076-2078$.

(10) Hermawan, H.; Dubé, D.; Mantovani, D. Development of Degradable Fe-35Mn Alloy for Biomedical Application. Adv. Mater. Res. 2007, 15-17, 107-112.

(11) Hermawan, H.; Alamdari, H. Iron-manganese: New Class of Metallic Degradable Biomaterials Prepared by Powder Metallurgy. Powder Metallurgy. 2008, 51, 38-45.

(12) Schinhammer, M.; Steiger, P.; Moszner, F.; Löffler, J. F.; Uggowitzer, P. J. Degradation Performance of Biodegradable Fe-Mn-C(-Pd) Alloys. Mater. Sci. Eng., C 2013, 33 (4), 1882-1893.

(13) Liu, B.; Zheng, Y. F. Effects of Alloying Elements (Mn, Co, Al, W, Sn, B, C and S) on Biodegradability and in Vitro Biocompatibility of Pure Iron. Acta Biomater. 2011, 7 (3), 1407-1420.

(14) Obayi, C. S.; Tolouei, R.; Paternoster, C.; Turgeon, S.; Okorie, B. A.; Obikwelu, D. O.; Cassar, G.; Buhagiar, J.; Mantovani, D. Influence of Cross-Rolling on the MicroTexture and Biodegradation of Pure Iron as Biodegradable Material for Medical Implants. Acta Biomater. 2015, 17, 68-77.

(15) Cheng, J.; Huang, T.; Zheng, Y. F. Relatively Uniform and Accelerated Degradation of Pure Iron Coated with Micro-Patterned Au Disc Arrays. Mater. Sci. Eng., C 2015, 48, 679-687.

(16) Zhu, S.; Huang, N.; Xu, L.; Zhang, Y.; Liu, H.; Lei, Y.; Sun, H.; Yao, Y. Biocompatibility of Fe-O Films Synthesized by Plasma Immersion Ion Implantation and Deposition. Surf. Coat. Technol. 2009, 203 (10-11), 1523-1529.

(17) Latifi, A.; Imani, M.; Khorasani, M. T.; Joupari, M. D. Electrochemical and Chemical Methods for Improving Surface Characteristics of 316L Stainless Steel for Biomedical Applications. Surf. Coat. Technol. 2013, 221, 1-12.

(18) Cai, Z.; Nakajima, H.; Woldu, M.; Berglund, A.; Bergman, M.; Okabe, T. In Vitro Corrosion Resistance of Titanium Made Using Different Fabrication Methods. Biomaterials 1999, 20, 183-190.

(19) Lorenzetti, M.; Dogša, I.; Stošicki, T.; Stopar, D.; Kalin, M.; Kobe, S.; Novak, S. The Influence of Surface Modification on Bacterial Adhesion to Titanium-Based Substrates. ACS Appl. Mater. Interfaces 2015, 7, 1644-1651.

(20) Alonso Frank, M.; Boccaccini, A. R.; Virtanen, S. A Facile and Scalable Method to Produce Superhydrophic Stainless Steel Surface. Appl. Surf. Sci. 2014, 311, 753-757. 
(21) Kunzler, T. P.; Drobek, T.; Schuler, M.; Spencer, N. D. Systematic Study of Osteoblast and Fibroblast Response to Roughness by Means of Surface-Morphology Gradients. Biomaterials 2007, 28, 2175-2182.

(22) Zheng, C.Y.; Nie, F.L.; Zheng, Y.F.; Cheng, Y.; Wei, S.C.; Valiev. R.Z. Enhanced in Vitro Biocompatibility of Ultrafine-grained Biomedical NiTi Alloy with Microporous Surface. Appl. Surf. Sci. 2011, 257, 9086- 9093.

(23) Wang, X. .; Li, D. . Mechanical and Electrochemical Behavior of Nanocrystalline Surface of 304 Stainless Steel. Electrochim. Acta 2002, 47, 3939-3947.

(24) Ranella, a.; Barberoglou, M.; Bakogianni, S.; Fotakis, C.; Stratakis, E. Tuning Cell Adhesion by Controlling the Roughness and Wettability of 3D Micro/nano Silicon Structures. Acta Biomater. 2010, 6 (7), 2711-2720.

(25) Makro F4-220 Produktinfo KV.DOC-01/00 Material Data Sheet Siliciumcarbid ESKSIC GmbH.

(26) Mikro F230-1200 KV-Laser.DOC-02/06, Material Data Sheet Siliciumcarbid ESKSIC GmbH.

(27) Kokubo T.; Takadama H. How Useful is SBF in Predicting In Vivo Bone Bioactivity? Biomaterials. 2006, 27, 2907-2915.

(28) American Society for Testing and Materials. ASTM-G31-72, Standard Practice for Laboratory Immersion Corrosion Testing of Metals. In: Annual book of ASTM standards. Philadelphia (PA): ASTM; 2004

(29) Schneider, M.; Kremmer, K.; Lämmel, C.; Sempf, K.; Herrmann, M. Galvanic Corrosion of Metal/Ceramic Coupling. Corros. Sci. 2014, 80, 191-196.

(30) Boudard, D.; Forest, V.; Pourchez, J.; Boumahdi, N.; Tomatis, M.; Fubini, B.; Guilhot, B.; Cottier, M.; Grosseau, P. In Vitro Cellular Responses to Silicon Carbide Particles Manufactured through the Acheson Process: Impact of Physico-Chemical Features on pro-Inflammatory and pro-Oxidative Effects. Toxicol. In Vitro 2014, 28, 856-865.

(31) Nordsletten, L.; Høgåsen, A. K. M.; Konttinen, Y. T.; Santavirta, S.; Aspenberg, P.; Aasen, A. O. Human Monocytes Stimulation by Particles of Hydroxyapatite, Silicon Carbide and Diamond: In Vitro Studies of New Prosthesis Coatings. Biomaterials 1996, $17(15), 1521-1527$.

(32) Onneby, C.; Pantano, C. Silicon oxycarbides formation on $\mathrm{SiC}$ surfaces and the SiC/SiO2 interface, J. Vac. Sci. Technol. 1997, A 15, 1597-1062.

(33) Zhang, F.; Kang, E.T.; Neoh, K.G.; Peng, W.; Tan, K.L. Surface modification of stainless steel by grafting of poly(ethylene glycol) for reduction in protein adsorption. Biomaterials 2001, 22, 1541-1548. 
(34) Haïdopoulos, M.; Turgeon, S.; Laroche, G.; Mantovani, D. Surface modifications of 316 stainless steel for the improvement of its interface properties with RFGD-deposited fluorocarbon coating. Surf. Coat. Technol. 2005, 197, 278-287.

(35) Naseri, N.; Yousefzadeh, S.; Daryaei, E.; Moshfegh, A.Z. Photoresponse and $\mathrm{H}_{2}$ production of topographically controlled PEG assisted Sol-gel $\mathrm{WO}_{3}$ nanocrystalline thin films. Int. J. Hydrogen Energy 2011, 36, 13462-13472.

(36) Feng, Z.C.; Cheng, X.Q.; Dong, C.F.; Xu, L.; Li, X.G. Passivity of 316L stainless steel in borate buffer solution studied by Mott-Schottky analysis, atomic absorption spectrometry and X-ray photoelectron spectroscopy. Corros. Sci. 2010, 52, 3646-3653.

(37) Chongdar, S.; Gunasekaran, G.; Kumar, P. Corrosion Inhibition of Mild Steel by Aerobic Biofilm. Electrochim. Acta 2005, 50 (October 2004), 4655-4665.

(38) Nasrazadani, S. The Application of Infrared Spectroscopy to a Study of Phosphoric and Tannic Acids Interactions with Magnetite (Fe3O4), Goethite $(\alpha-\mathrm{FEOOH})$ and Lepidocrocite ( $\gamma$-FeOOH). Corros. Sci. 1997, 39 (1), 1845-1859.

(39) Revie, W.R.; Uhlig, H.H. Corrosion and Corrosion Control, fourth ed. John Wiley \& Sons, Hoboken, New Jersey, 2008

(40) Keenan, C.R.; Goth-Goldstein, R.; Lucas, D.; Sedlak, D.L. Oxidative Stress Induced by Zero-valent Iron Nanoparticles and Fe(II) in Human Bronchial Epithelial Cells, Environ. Sci. Technol. 2009, 43, 4555-4560.

(41) Nday, C.M.; Malollari, G.; Petanidis, S.; Salifoglou, A. In Vitro Neurotoxic Fe(III) and Fe(III)-chelator Activities in Rat Hippocampal Cultures. From Neurotoxicity to Neuroprotection Prospects, J. Inorg. Biochem. 2012, 117, 342-350.

(42) Washburn, N. R.; Yamada, K. M.; Simon, C. G.; Kennedy, S. B.; Amis, E. J. HighThroughput Investigation of Osteoblast Response to Polymer Crystallinity: Influence of Nanometer-Scale Roughness on Proliferation. Biomaterials 2004, 25, 1215-1224.

(43) DM Brunette. Principles of cell behavior on titanium surfaces and their application to implanted devices. In: Brunette DM, Tengvall P, Textor M, Thomsen P, editors. Titanium in medicine. Berlin and Heidelberg: Springer; 2001; pp 485-512.

(44) Deligianni, D. D.; Katsala, N. D.; Koutsoukos, P. G.; Missirlis, Y. F. Effect of Surface Roughness of Hydroxyapatite on Human Bone Marrow Cell Adhesion, Proliferation, Differentiation and Detachment Strength. Biomaterials 2000, 22, 87-96.

(45) Anselme, K.; Bigerelle, M.; Nol, B.; Iost, a.; Hardouin, P. Effect of Grooved Titanium Substratum on Human Osteoblastic Cell Growth. J. Biomed. Mater. Res. 2002, 60, 529-540.

(46) Allenstein, U.; Ma, Y.; Arabi-Hashemi, a.; Zink, M.; Mayr, S. G. Fe-Pd Based Ferromagnetic Shape Memory Actuators for Medical Applications: Biocompatibility, Effect of Surface Roughness and Protein Coatings. Acta Biomater. 2013, 9, 5845-5853. 


\section{Table of Contents}

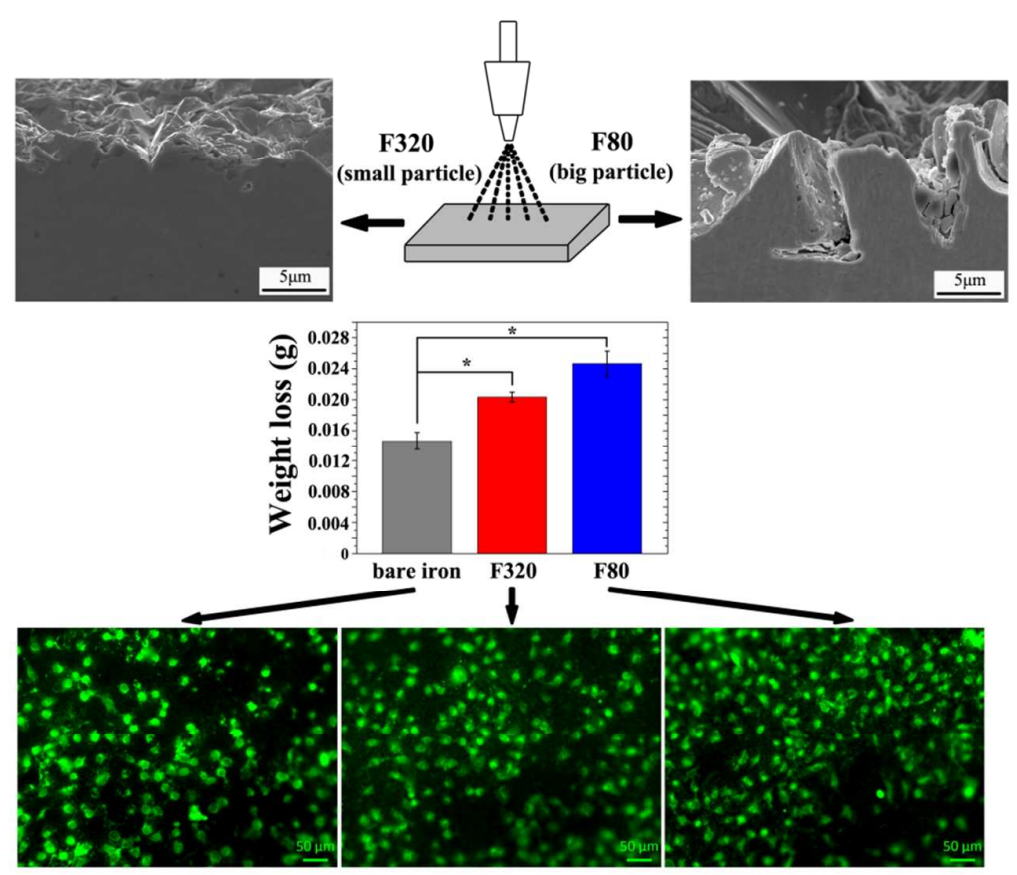

